\title{
Os que ficam: comunidade portuguesa em Antuérpia, 1596 - 1606
}

\author{
Maria Amélia Oliveira \\ oliveiraamelia@hotmail.com
}

\section{Resumo}

Este trabalho examina a presença da comunidade portuguesa em Antuérpia, após a conquista da cidade pelas tropas de Filipe II e o embargo imposto ao comércio com as Províncias Unidas. A partir de 1585, acentua-se a emigração de mercadores para cidades vizinhas, nomeadamente Amesterdão. Em geral, a historiografia nacional tem dedicado atenção aos portugueses que trocam a cidade por novos centros mercantis, e ao seu contributo para os negócios nessas praças. No entanto, Antuérpia conservou algum peso enquanto praça financeira, e nela mantiveram residência vários mercadores portugueses. A cronologia em estudo compreende dois cortes temporais: 1596 e 1606. Os resultados da análise revelam que neste intervalo de tempo se assiste a uma adaptação das práticas comerciais, que trazem novas oportunidades de negócio. Em Antuérpia, verificamos que os impérios português e castelhano se tocam, e o modo como os mercadores portugueses disso beneficiam. Com base em informações extraídas de atos notariais que incluem procurações, protestos de letras, cartas de quitação e testamentos, o trabalho identifica esses mercadores, quem são os seus parceiros de negócio, os espaços geográficos com os quais mantêm contacto e por onde transitam, o tipo de atividades económicas que desenvolvem, mas também com quem casam, quem são os seus herdeiros, como se tecem os seus laços familiares. O resultado é uma caracterização socioeconómica da comunidade portuguesa em Antuérpia no período considerado.

Palavras-chave: Antuérpia, Época Moderna, comunidade portuguesa, redes comerciais, perfil sócio-económico.

\begin{abstract}
This paper examines the presence of the Portuguese community in Antwerp, after the conquest of the city by the troops of Philip II and the embargo imposed on trade with the United Provinces of the Netherlands. From 1585 onwards, there is an increase in the migration of merchants to neighbouring cities, such as Amsterdam. In general, Portuguese historiography has payed particular attention to the Portuguese who leave Antwerp for new mercantile centres, and to their contribution to business in these new places. However, Antwerp retained some weight as a financial market, and several Portuguese merchants remained in the city. The chronology under study comprises two time slots: 1596 and 1606. The results of the analysis reveal that in this period there is an adaptation of their commercial practices, with new business opportunities. In Antwerp, we see how the Portuguese and Castilian empires intersect, and the way Portuguese merchants benefit from it. Based on information from notarial acts such as powers of attorney, bills of exchange, settlement briefs and wills, this work identifies merchants, their business partners, transit and trading places, different kinds of economic activities they carry out, but also whom they marry, their heirs, how their family ties are woven. The result is a socio-economic profile of the Portuguese community in Antwerp around the turn of the 16th century.
\end{abstract}

Keywords: Antwerp, Early Modern History, Portuguese community, commercial networks, socio-economic profile. 


\section{Introdução}

Este trabalho pretende dar a conhecer os negociantes portugueses presentes em Antuérpia, num momento em que este centro da economia global começa a ceder terreno em favor de Amesterdão. Com efeito, até ao início da guerra dos 80 anos (1568-1648) e em concreto, até ao encerramento do seu porto, Antuérpia foi um importante centro de redistribuição, entre o Norte e o Sul da Europa, de produtos de origem europeia e ultramarina. Deste comércio, os portugueses asseguravam uma fatia substancial: num primeiro tempo através da Feitoria Portuguesa, que representou os interesses comerciais da monarquia até ao seu encerramento formal em 1549, em seguida através do comércio privado promovido por mercadores e companhias privadas reunidos na Nação portuguesa, oficialmente reconhecida pelas autoridades municipais em 1511. De 1585 em diante, ultrapassado o primeiro impacto dos tumultos e do embargo do porto, os portugueses aí residentes continuaram a participar ativamente, a partir daí, numa economia global, e Antuérpia tornou-se mais um ponto em que os dois impérios, português e espanhol, se cruzavam, e tal facto não passou despercebido aos mercadores portugueses, como adiante veremos. ${ }^{1}$

As redes mercantis que tinham construído, estreitadas por laços de parentesco e de mútua confiança, permitiram manter os fluxos comerciais e financeiros entre a comunidade de Antuérpia e os demais espaços imperiais, inclusive com terras consideradas como inimigas, como eram as Províncias Unidas e os seus portos da Zelândia. Com efeito, Antuérpia só fícou verdadeiramente relegada para segundo plano após as primeiras décadas do século XVII ${ }^{2}$.

Invertendo uma tendência que se tem verificado na historiografia recente ${ }^{3}$, este trabalho não considera Antuérpia apenas como um viveiro de onde partem os mercadores que farão a

\footnotetext{
1 "Ces guerres nouvelles imposent davantage de frais aux républiques, mais proposent aux entrepreneurs des combinaisons profitables et des occasions exceptionnelles. Les hommes d'affaires ne manquent pas de mettre au service des princes leurs connexions financières et marchandes." - SILVA, José Gentil da - "Trafics du Nord, marchés du «Mezzogiorno», finances génoises: recherches et documents sur la conjoncture à la fin du XVIe siècle". Revue du Nord. [Em Linha] Lille. Vol. 41, n. ${ }^{\circ} 162$ (Abril-Junho 1959) p. 129.

2 "It was only at the end of 1590s that the money market in Antwerp began to collapse. The third default by the Spanish state in 1596 provoked a wave of bankruptcies in Spain itself and in Antwerp. For finance, although no longer for industry or trade, Antwerp still remained the centre until the first decades of the 17th century." SPUFFORD, Peter - "From Antwerp and Amsterdam to London: The Decline of Financial Centres in Europe". De economist. [Em Linha] Vol. 154, n. ${ }^{\circ} 2$ (Fev. 2006) p. 158.

${ }^{3}$ Vide Cátia ANTUNES com vasta bibliografia dedicada à presença de cristãos-novos em Amesterdão, como por exemplo Globalisation in the Early Modern period: the economic relationship between Amsterdam and Lisbon, 1640-1705. Amesterdão: Aksant, 2004; ou Jorun POETTERING que estuda a comunidade portuguesa em Hamburgo em Migrating Merchants: Trade, Nation and Religion Between Hamburg and Portugal in the 17th Century. Berlin, Boston: De Gruyter Oldenbourg, 2019; ou Francesca TRIVELLATO que se debruça sobre os judeus sefarditas no Livorno em The familiarity of strangers the Sepahrdic diaspora, Livorno, and the crosscultural tradein the early modern period. New Haven, Londres: Yale University Press, 2009; ou ainda a tese de doutoramento de Florbela Veiga FRADE sobre a importância da família para as relações económicas dos sefarditas em Antuérpia: As relações económicas e sociais das comunidades sefarditas portuguesas - O trato e a família, 1532 - 1632. Lisboa: Faculdade de Letras da Universidade de Lisboa. 2006.
} 
riqueza de Amsterdão nem aplica uma análise centrada no prisma cristão-novo/sefardita. Pelo contrário, pretende dar a conhecer esta comunidade, traçando o seu perfil económico e social tal como se apresenta, e deste modo confirmar que não houve um desmantelamento imediato da sua centralidade nas redes mercantis portuguesas, europeias e mesmo ultramarinas, mesmo com o aumento de protagonismo de Amesterdão. Os atos notariais redigidos no cartório de Gillis van de Bossche são a fonte primária selecionada, dada a abundância de referências a agentes portugueses e às suas atividades.

\section{Estado de arte}

A comunidade em estudo não é desconhecida da historiografia portuguesa ou estrangeira. Aliás, toda a presença portuguesa no noroeste europeu na Época Moderna tem sido estudada sob diversos ângulos - económico, sociológico, cultural, talvez mais no estrangeiro do que em Portugal. A bibliografia pode ser dividida em dois grandes blocos.

O primeiro bloco é constituído por trabalhos que se dedicam à caracterização económica e sociológica dos mercadores e das suas atividades. Nelas encontramos descrições de negócios, listas de agentes mercantis, genealogias das famílias mais importantes, descrições dos produtos comercializados, etc. Em geral, os seus autores são os primeiros a abordar o tema de uma forma mais sistemática, sobretudo através de um exercício de identificação e caracterização dos vários elementos que compõem o quadro da presença portuguesa ${ }^{4}$. São obras produzidas há várias décadas, que por vezes se apoiam elas próprias em trabalhos anteriores. Estas foram tomadas como uma porta de entrada para nos inteirarmos da temática em estudo ${ }^{5}$, como ocorre com a monografia de J. A. Goris ${ }^{6}$ para a primeira metade do século XVI.

Ainda dentro deste primeiro bloco há que destacar a obra de Hans Pohl que orientará o nosso trabalho ${ }^{7}$. Pohl coloca como ponto de partida o ano de 1567 do seu estudo, precisamente o momento em que J. A. Goris termina o seu estudo. É como uma passagem do testemunho, e de facto entre uma e outra obra temos uma excelente descrição dos 150 anos de presença dos mercadores portugueses em Antuérpia. Trata-se de uma obra muito abrangente e pormenorizada, descrevendo a Nação portuguesa enquanto entidade, as suas relações com as autoridades da cidade, as principais famílias, as atividades profissionais, a participação no

\footnotetext{
${ }^{4}$ FREIRE, A. Braamcamp - Notícias da Feitoria da Flandres: precedidas dos Brandões poetas do cancioneiro. Lisboa: Arquivo Histórico Português, 1920.

${ }^{5}$ FRADE, Florbela Veiga - As relações económicas e sociais das comunidades sefarditas portuguesas - O trato e a familia, $1532-1632$...

${ }^{6}$ GORIS, Jan Albert - Étude sur les Colonies Marchandes Méridionales (Portugais, Espagnols, Italiens) à Anvers de 1488 à 1567: Contribution à l'Histoire des Débuts du Capitalisme Moderne. Nova Iorque: Franklin, 1971.

${ }^{7}$ POHL, Hans - Die Portugiesen in Antwerpen (1567-1648): zur Geschichte einer Minderheit. Wiesbanden: Steiner, 1977.
} 
comércio, seguros, concessão de crédito, com vários anexos e índices. Em termos de fontes primárias, a obra tem o grande benefício de identificar dois fundos notariais que contêm um grande número de atos de diferente natureza, aos quais recorre amiúde para fundamentar as suas observações. O facto de Pohl não adotar o prisma "cristão-novo" não o impede se referir à importância das suas relações familiares no mundo dos negócios.

Observa-se, entretanto, uma evolução na historiografia: o grupo de mercadores em análise não é constituído por portugueses tout court, mas por portugueses cristãos-novos. Esta nova caracterização do grupo tem várias implicações ao nível da análise do comportamento mercantil. Assim, as relações interpessoais e familiares assumem uma importância acrescida, tal como as ações da Inquisição e a intervenção dos governantes, umas vezes mais coniventes com a participação de "gentes de Nação" nas esferas económica e financeira, outras vezes mais restritivos. Neste segundo bloco de obras, parte-se dos trabalhos de caracterização e descrição da comunidade e do trato, para avançar algumas interpretações. Alguns autores optam por fazer uma análise a partir da perspetiva da diáspora da nação hebraica ${ }^{8}$. Este ponto de observação permite um questionamento diferente da comunidade em estudo, nomeadamente a relação entre etnia/religião/confiança/negócios.

A pluralidade de perspetivas e temáticas são a prova de que a participação portuguesa no comércio internacional da Época Moderna a partir de praças estrangeiras é uma matéria de investigação atrativa e potencialmente reveladora de tendências do mundo de negócios nesses espaços. São inúmeras as fontes primárias à disposição do investigador, nomeadamente em Antuérpia. A título de exemplo, Puttevils usa registos de cobrança do imposto do $1 \%$ sobre o valor das exportações, Pohl recorre a documentos notariais, documentos da Nação portuguesa, impostos, transações de imóveis, listas de estrangeiros tornados cidadãos da cidade, entre outros. Pelo que nos foi dado perceber, muitos destes dados não foram consultados até à data pelos historiadores nacionais.

\footnotetext{
${ }^{8}$ A título exemplificativo veja-se Jorun Poettering, em Migrating Merchants: Trade, Nation and Religion Between Hamburg and Portugal in the 17th Century, que avalia o grau de integração na sociedade local de Hamburgo de mercadores cristãos-novos e as implicações que a integração (limitada) tinha no seu sucesso comercial; Francesca Trivellato, que aborda as relações comerciais da comunidade sefardita do Livorno de seiscentos, que usa para aferir a importância da religião na confiança entre comerciantes de diferentes culturas (TRIVELLATO, Francesca - The familiarity of strangers...); Christopher Ebert, que avança com uma análise sobre seguros marítimos (EBERT, Christopher - "Early Modern Atlantic Trade and the Development of Maritime Insurance to 1630". Past and Present. [Em Linha]. Vol. 213, n. ${ }^{\circ} 1$ (Nov. 2011) pp. 87-114; ou ainda Jeroen Puttevils que estuda a esttruturas financeiras que permitiram o crescimento commercial de Antuérpia (PUTTEVILS, Jeroen - "«Eating the bread out of their mouth»: Antwerp's export trade and generalized institutions, 1544-5". The Economic History Review. [Em Linha] Vol 68, nº 4 (Maio 2015) pp. 1339-1364).
} 


\section{As fontes primárias: os atos notariais}

Enquanto fonte primária, os atos notariais constituem um repositório rico em informações ${ }^{9}$. O ano de $1596^{10}$ impôs-se de per se, uma vez em que foi o primeiro ano pós1585, parte de uma série de livros notariais pertencentes ao cartório de Gillis van den Bossche, ao qual recorreram vários mercadores portugueses. Não foi o único tabelião de Antuérpia de que se serviram, como se pode concluir das referências nos próprios documentos estudados. Porém, não se conseguiu identificar outro notário cujos livros revelassem tal abundância de referências a negociantes portugueses ${ }^{11}$. Por sua vez, o ano de 1606 permite apreciar a evolução da presença portuguesa na cidade e das suas atividades, 10 anos volvidos sobre o primeiro corte temporal. ${ }^{12}$

$\mathrm{Na}$ abordagem aos livros de notário, há que ter presente aquilo que não registam. $\mathrm{O}$ mercador não necessita de tornar num instrumento público um empréstimo que concedeu a um sócio ou parceiro da sua maior confiança, não dá quitação de uma letra de câmbio devidamente paga, não regista atos de compra e venda em que tem plena confiança na contraparte. Os atos notariais são, em grande medida, e neste domínio de estudo, o repositório do que correu ou pode correr mal, pois os mercadores recorrem aos serviços do tabelião para garantir o cumprimento de contratos ${ }^{13}$.

\section{Metodologia}

A seleção dos documentos a tratar, isto é, aqueles que mencionam portugueses residentes ou estantes em Antuérpia constituiu o primeiro passo da investigação que suporta esta contribuição. De seguida, procedeu-se à compilação dos dados em folhas Excel, organizados por atos jurídicos, em que se incluíram informações relativas às tipologias de transações, relações jurídicas entre os agentes e mercadorias e locais abrangidos, além da identificação dos agentes envolvidos e seus atributos sociais e familiares.

Note-se que de um mesmo documento se podem deduzir diferentes atos jurídicos. A título de exemplo, num documento relativo a uma procuração para a cobrança de uma dívida é também referido um ato anterior de compra e venda, o qual se encontra na origem da dívida

\footnotetext{
${ }^{9}$ CLAVERÍAS, Belén Moreno - ¿Cómo se construye la historia económica? El uso de los documentos notariales para las práticas de historia económica en el marco del EEES. IX Encuentro de Didáctica de la Historia Económica, Toledo 24 e 25 de junho de 2010. [Em Linha ] Toledo: [s.n.], 2010. pp. 3-4.

${ }^{10}$ Documentos reunidos no livro com a cota N\#3568, abrangendo todo o ano de 1596. Ver Gillis, Van den Bossche - Protocollen, en staten en rekeningen, 1596-1596. N\#3568 (fols. 1-422) (FelixArchief, Stadsarchief Antwerpen).

${ }^{11}$ Os livros do notário Gillis van den Bossche foram abundantemente consultados e citados por Hans Pohl, a principal referência deste trabalho.

${ }^{12}$ Documentos reunidos nos livros com as cotas N\#3584, N\#3585 e N\#3586.

${ }^{13}$ GELDERBLOM, Oscar - Cities of Commerce: the institutional foundations of the international trade in the Low Countries, 1250-1650. New Jersey: Princeton University Press, 2013. p. 100
} 
contraída; num documento relativo a uma procuração para administrar os negócios do contrato de Angola, infere-se a obtenção desse contrato junto da Coroa. Este contrato com a Coroa passa a ser tratado como um novo ato, por envolver agentes relacionados com a comunidade, por exemplo, através de relações de parentesco.

Esta divisão do documento em vários registos/atos jurídicos permite captar as várias etapas, espaços e indivíduos envolvidos, mas implica, igualmente, uma leitura atenta do resultado obtido com a utilização dos filtros do Excel, em ordem a evitar duplicações de contagens de ocorrências, pois no mesmo documento frequentemente ocorrem vários atos abrangidos pela mesma classificação temática (p.ex. comércio), mas que têm que ver com o mesmo documento notarial. Assim, e de novo um exemplo: num documento relativo a um crédito temos um ato de quitação desse crédito e ainda a menção a uma procuração ${ }^{14}$, logo temos dois registos, mas na realidade trata-se de um único e mesmo crédito. A forma de contornar esta multiplicação de atos é considerar apenas o documento, quando se passa para a produção de estatísticas.

Outro elemento relevante a considerar são os atos com datas anteriores aos dois anos de referência. Como exemplo, a certificação de assinatura tem lugar em 1596 ou 1606, mas o documento, cuja assinatura tem de ser certificada, pode ter sido lavrado em 1595 ou 1604. Entende-se que é mais útil adicionar esses atos de anos anteriores aos atos do ano 1596 ou, no caso de atos a partir de 1597, aos de 1606, ainda que, a bem da verdade, se encontrem fora dos intervalos considerados. Essa opção foi tomada por dois motivos. Se esses atos fossem considerados isoladamente, não teriam relevância estatística por se tratar de um número reduzido de situações; por outro lado - e razão mais importante - mesmo sendo de anos transatos, continuam a produzir efeitos jurídicos, pois de outro modo não seriam mencionados pelo notário.

\section{Análise económica}

Uma das conclusões que podemos de imediato extrair é a de que a atividade económica dos agentes portugueses não diminuiu entre os dois períodos estudados. Os números falam por si: para o ano de 1596 são identificados 64 documentos em que são mencionados portugueses residentes ou estantes em Antuérpia; para 1606 identificam-se 245.

Segue uma análise mais fina dos registos das atividades económicas que envolvem esses agentes para os dois anos em estudo.

\footnotetext{
${ }^{14}$ Por exemplo: N\#3568_0034, fols. 352-354.
} 
Gráfico 1 - Repartição dos atos notariais em 1596

\section{Repartição atos notariais - 1596}

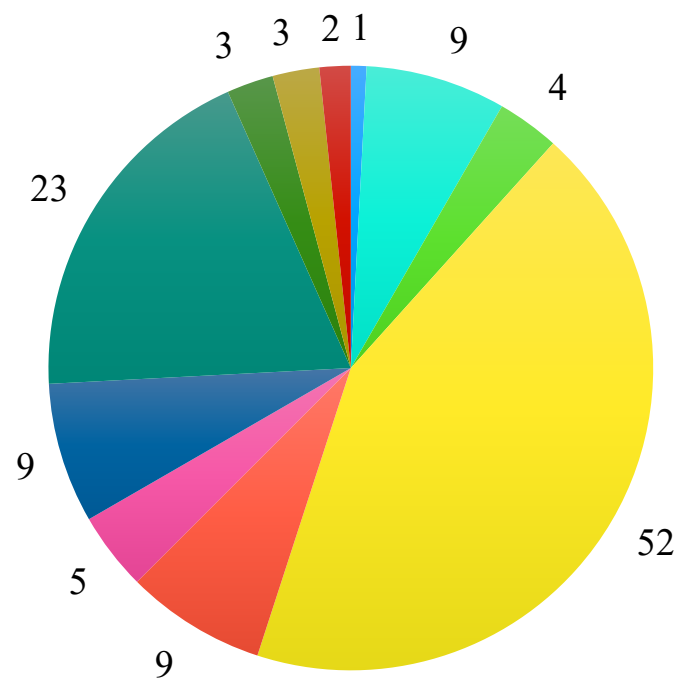

CASAMENTO
COMÉRCIO
CONTRATO
CRÉDITO
HERANÇA
MOBILIDADE
NEGÓCIO
- OPERAÇÃO FINANCEIRA
- SEGURO
SOCIABILIDADE
- TRABALHO

FONTE: FelixArchief, Stadsarchief Antwerpen, N\#3568

Gráfico 2 - Repartição dos atos notariais em 1606

Repartição atos notariais - 1606

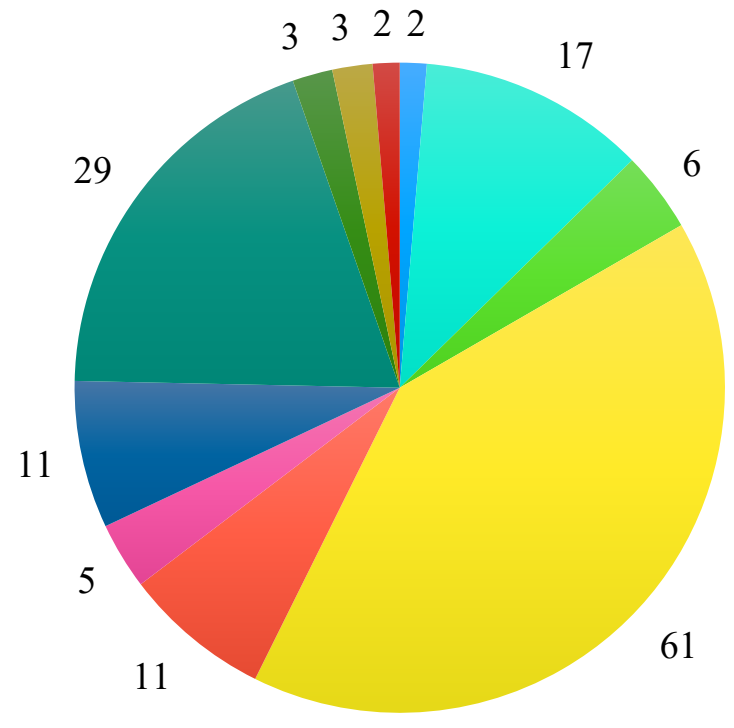

- CASAMENTO
COMÉRCIO
CONTRATO
CRÉDITO
HERANÇA
MOBILIDADE
nEGÓCIO
- OPERAÇÃO FINANCEIRA
- SEGURO
- SOCIABILIDADE
- TRABALHO

FONTE: FelixArchief, Stadsarchief Antwerpen, N\#3584, N\#3585 e N\#3586.

Os números e a sua representação pedem alguns esclarecimentos e observações, nomeadamente quanto ao teor das categorias usadas. 
O comércio não está plasmado diretamente em contratos clássicos de compra e venda de mercadorias, mas infere-se do teor das procurações ou declarações ${ }^{15}$. Os atos explícitos de comércio representam apenas 6 dos 64 documentos de 1596 (9,4\% do total). Certamente há mais atividades de compra e venda, porque as letras de câmbio e o recurso ao crédito, duas temáticas que serão analisadas adiante, são meios de pagamento tipicamente usados no comércio. Por outro lado, o seu número relativamente baixo pode ter que ver com o facto de estes homens nem sempre plasmarem num instrumento público esse tipo de contratos, quando os negócios se faziam em círculos de família ou com pessoas da sua confiança ${ }^{16}$. Ainda assim, são muito diversas as seis transações em causa: temos um monopólio de 20 anos para importação de pedra ume e sulfato ferroso, a venda de holandas, um conhecido tipo de tecido, ou de diversas peças em prata lavrada de uma herança, através de um pregoeiro. Acrescente-se a compra e venda de algodão, açúcar e marfim, ligados ao contrato de monopólio de comércio de S. Tomé, que já não passam pelo porto de Antuérpia, mas cuja venda é assegurada por mercadores portugueses estantes em Honte (parte ocidental do rio Escalda) com procuração para receberem e venderem os produtos.

Os espaços abrangidos por essas transações englobam a Zelândia, a Ibéria, locais de obediência ao monarca espanhol, e S. Tomé. Em Antuérpia só tem lugar a venda das pratas. Esta pouca expressividade de atos relacionados com o comércio poderá decorrer da já mencionada relação de confiança entre mercadores, que os leva a abdicar de mais encargo financeiro como é a passagem pelo notário, mas certamente decorre também dos efeitos do embargo ao porto da cidade. Os parceiros escolhidos são igualmente portugueses, exceto no caso do monopólio da pedra ume concedido pelo monarca espanhol, em que Sebastião Vaz, com uma participação em 1/5 dos proveitos, surge associado a dois flamengos, Cornille Carroy e Jean Cools.

No universo dos 245 documentos relativos a 1606 temos uma percentagem semelhante, $8,9 \%$ (22 documentos). Aqui as mercadorias coloniais têm um pouco mais de expressão: há 1 referência ao pau brasil, outra a mercadorias do Brasil não especificadas, 4 a pérolas e diamantes, 3 a açúcar e gengibre e outra a caixas de canela. Nos produtos europeus temos 5 menções a panos e fardos de lã, trigo, sal, objetos em cobre, estanho e fivelas para sapateiros e

\footnotetext{
${ }^{15}$ Para a caracterização do comércio, Hans Pohl, por exemplo, baseia-se mais em fontes secundárias, como a obra Lettres Marchandes d'Anvers de Valentín Vázquez de Prada e não predominantemente em atas do notário. Ver VÁZQUEZ DE PRADA, Valentín - Lettres Marchandes d'Anvers. Paris, S.E.V.P.E.N., 1960; e POHL, Hans Die Portugiesen in Antwerpen (1567-1648)... p 139 e seguintes.

16 "the public registration of private contracts, whether by town secretaries or notaries, covered only a small fraction of all commercial transactions"; "merchants used notarial deeds to formalize the extension of agency relations beyond the closed networks of family and friends"; - GELDERBLOM, Oscar - Cities of Commerce... pp. 94 e 93 respetivamente.
} 
por fim conservas em azeite. Hamburgo é o porto onde chegam os produtos exóticos, mas também o sal, enquanto que as mercadorias europeias circulam por França (Rouen, Lille, Calais) com destino a Lisboa. Para garantirem que a sua exportação vai decorrer sem problemas ao longo do seu percurso por terra e mar, os mercadores solicitam ao notário uma declaração de que os bens que não passam por terras inimigas ${ }^{17}$. Não há menção quanto à origem ou destino das pedras preciosas, mas sabe-se que circulariam por terra ${ }^{18}$. Um dos compradores (Gaspar de Orta) está identificado como residindo em 1603 em Veneza, um dos pontos de chegada das rotas do Oriente. Em 1606 Matheo De Renzy, que ainda não pagou a Diogo Rodrigues de Paiva os 33 diamantes que estão na sua posse, encontra-se em Londres. O mercador português tem de recorrer aos serviços do seu agente flamengo Jan Van Dale para poder recuperar o rendimento da venda. Este é um dos exemplos que revelam que em 1606 há mais contactos entre portugueses e estrangeiros do que 10 anos antes. Estes são transportadores em França, procuradores em Hamburgo e Rouen, vendedores ou compradores.

As referências aos seguros também demonstram como a cidade é mais um interface do que um porto de chegada ou partida de mercadorias. Em 1596 foram exarados 3 documentos relativos a naus que se perderam ou foram apresadas, cujo seguro agora é reclamado; 1606 vê o número de declarações ou intimações subir para 7. Interessa sobretudo ver os portos envolvidos: Zelândia, Baía - Lisboa para 1596; Ancona - Sevilha, Hamburgo - Laredo, Porto - Hamburgo, Hamburgo - Sevilha, Calais - Lisboa para 1606. Note-se que nenhuma embarcação tinha Antuérpia como porto de partida ou destino. Ainda assim, os seguros eram tomados nesta praça, em sociedades que envolviam negociantes estrangeiros (sobretudo flamengos) e portugueses. Das 4 listas de seguradores intimados a pagar, a participação nacional é de 8, 25 e $50 \%$, sendo alguns nomes recorrentes, tanto de portugueses como de estrangeiros, o que pode indiciar uma apetência pessoal para o investimento em seguros. ${ }^{19}$ Entre os seguradores portugueses contam-se os Ximenes, uma das famílias com maior renome na praça.

\footnotetext{
17 "y que las dichas piecas de cozina arriba referidas son hechas y fabricadas en esta dicha villa de Enberes y que no entraron en tierras ny lugares de los rebeldes de Holanda y Gelanda enemigas de su Magestad Cattolica y Altesas Serenissimas ny les pagaron diesmo ny derechos ningunos."; fols. 75-76: "y que dichas brochas de çapateros fueron hechas y fabricadas en la villa de Liega $<$ y sus contornos $>$ ques de la obediência de su Alteza el principe Arnesto obispo de la dicha villa y en el ympero y que no pagaron diesima ny derechos ningunos a los rebeldes de Holanda e Gelanda enemigos de su Magestad Cattolica y Alteza Serenissima ny entraron ny passaron por tierras ni lugares ocupados por los dichos rebeldes.”. Ver Gillis, Van den Bossche - Protocollen en staten, 1606-1606. N\#3586 (fols. 1-482) (FelixArchief, Stadsarchief Antwerpen), N\#3586, fols. 22-22v.

${ }^{18}$ POHL, Hans - Die Portugiesen in Antwerpen (1567-1648)... p. 197.

${ }^{19}$ Pohl refere que era comum esta comunidade segurar cargas de outras nações, de onde se pode concluir que gozavam de boa reputação na praça de Antuérpia, um aspeto importante, pois os seguros eram um ramo de negócio propício a abusos; pode ainda revelar que os portugueses tinham acesso a informação privilegiada da corte sobre movimentações de tropas, pirataria, etc. (POHL, Hans - Die Portugiesen in Antwerpen (1567-1648)... pp. 269270); EBERT, Christopher - "Early Modern Atlantic Trade and the Development of Maritime Insurance to 1630"... p. 105.
} 
Como se deduz da figura 1, é o crédito que mais leva os mercadores ao notário em 1596. Os atos (obrigações, quitações, procurações para cobrança, entre outros) figuram em 32 documentos, ou seja, metade do total do ano. Ainda que seja mais frequente o devedor encontrar-se em Antuérpia, há igualmente situações de crédito que envolvem empréstimos/ dívidas em Sevilha, Lisboa, Calais, Saint-Omer, Londres e Veneza (1596), para além de Pernambuco e outras partes do Brasil, Lille, Rouen e Medina del Campo (1606).

Em 1606 o crédito é abordado em 28\% dos documentos (69). Destes, 46,3\% são relativos a procurações para cobrança; em 1596, as procurações, afetam 31\% dos mercadores. Interessa ver qual era a outra parte do acordo. Em 1596, são 16 os estrangeiros com os quais estabelecem uma relação creditícia, e nela os portugueses tanto são devedores como credores. Destes estrangeiros, 11 são espanhóis, alguns dos quais militares. É de crer que essas cobranças decorram de empréstimos, pois não é feita qualquer referência a vendas. Com efeito, 1596 foi o ano da $3^{\text {a }}$ bancarrota de Filipe II, o que certamente teve repercussões negativas nos pagamentos atempados às tropas estacionadas na Flandres. Em 1606, as situações de endividamento com estrangeiros diminuem para apenas 12 atos de crédito. Aqui, o grosso dos créditos ocorre entre membros da comunidade portuguesa e tem que ver com atrasos no pagamento de letras de câmbio, vendas ou endossos, ou ainda, no caso de Maria Gomes, viúva de Nicolau Rodrigues de Évora, com dificuldades em fazer cobrar os créditos herdados do marido. Nicolau era irmão de Simão Rodrigues de Évora, um importante membro da comunidade, cuja riqueza lhe permitiu comprar a baronia de Rodes. Maria Gomes desloca-se várias vezes ao notário, ora para lavrar procurações para litigar em tribunal, ora para requerer pagamento de dívidas ou entrega de joias (que porventura teriam servido de caução), ora para dar quitação de créditos ${ }^{20}$.

O endosso ocorre entre membros da comunidade portuguesa, apenas com uma exceção. $\mathrm{O}$ ato pressupõe que o endossado acredite no pagamento do crédito que recebe em troco da quitação que vai passar ao endossante, e para isso é necessário um certo grau de confiança, que existe mais facilmente entre conhecidos ou mesmo parentes.

Uma das observações mais frequentes em relação a Antuérpia para este período é que se tornou uma praça financeira ${ }^{21}$. Destas situações de crédito (empréstimos, endossos, livranças) pode-se deduzir que os agentes económicos têm liquidez e que estão dispostos a emprestar a particulares, a parceiros de negócios ou à coroa espanhola. Desta relação com o Estado, destacam-se a livrança de 24 mil florins que Sebastião Vaz passou ao contador da artilharia do

\footnotetext{
${ }^{20} \mathrm{~N} \# 3586$. Entre 5 de agosto e 23 de novembro de 1606, Maria Gomes aparece em 10 documentos.

${ }^{21}$ SPUFFORD, Peter - "From Antwerp and Amsterdam to London: The Decline of Financial Centres in Europe"...; PINTO, Sara Maria Costa - A Companhia de Simón Ruiz. Análise espacial de uma rede de negócios no século XVI. [Em Linha] Porto: [Edição do Autor], 2012. p. 96.
} 
exército espanhol ${ }^{22}$, a quitação do empréstimo concedido por Luis Peres a Thialco Sikinga, procurador de Francisco de Verdugo, governador da Frísia ${ }^{23}$ (em 1596 ainda sob domínio filipino), e em particular a procuração de André Faleiro, passada em nome da gente da Nação (inferimos que da Nação portuguesa em Antuérpia), para que Domingos Cervena e Luis Rodrigues de Paiva estejam presentes na contagem do empréstimo concedido ao monarca, em $1606^{24}$, o ano da primeira suspensão de pagamentos de Filipe III.

As operações financeiras estão maioritariamente representadas no nosso corpus documental por letras de câmbio. Estas tornam-se muito presentes nos livros relativos a 1606 (245 atos, relativos a 130 letras), maioritariamente através de protestos do beneficiário contra o pagador renitente. Esta é mais uma prova da liquidez da praça de Antuérpia, onde afluem ordens de pagamento de vários espaços europeus, e da sua crescente importância como praça financeira. No caso dos mercadores portugueses, as letras permitem aferir os locais com que estavam mais em contacto. Estes estão ligados ou pela via do comércio (e as letras de câmbio são mais um complemento para o seu estudo, pois eram a forma mais comum de pagamento de e para espaços mais afastados na Europa); ou pela via dos empréstimos à administração filipina, pois os asentistas em Portugal e Espanha davam letras sobre os seus agentes em Antuérpia para pagar aos contadores ou pagadores espanhóis ${ }^{25}$.

Assim, até 1596 são referidas 12 letras: 3 de Madrid, 3 de Amsterdão, 2 de Francoforte; Hamburgo, Medina del Campo, Talavera e as feiras de Besançon aparecem uma vez. Há também a uma promessa de letra para Veneza ou Florença.

O quadro altera-se bastante 10 anos mais tarde: de Lisboa, que está ausente em 1596, chegam 40 letras $(30,7 \%)$. O mesmo se passa com Sevilha, que em 1606 é a segunda praça com mais letras de câmbio de e para Antuérpia (17,7\%), logo seguida de Medina del Campo (15,4\%). Os vários espaços do reino de Espanha (Medina, Sevilha e Valladolid) representam 35,4\% das letras. Daqui pode-se inferir que em 1606 os contactos comerciais e financeiros da comunidade portuguesa em Antuérpia eram maioritariamente com a Península Ibérica, em concreto, com os principais portos e feiras onde se trocavam os produtos coloniais - e no caso de Sevilha, a prata.

A questão coloca-se: como explicar a ausência de Lisboa em 1596? Haveria outra forma de transferência de capitais? Haveria menos negócios entre Lisboa e Antuérpia? Ou será que não havia protestos ou recusas e por isso não havia necessidade de recorrer ao notário? Podemos também apontar como hipótese o tipo de relações entre dadores, tomadores e beneficiários. Se

\footnotetext{
${ }^{22} \mathrm{~N} \# 3568$, fols. 291-292.

${ }^{23} \mathrm{~N} \# 3568$, fols. 261-261v.

${ }^{24} \mathrm{~N} \# 3586$, fols. $160-161$.

${ }^{25}$ POHL, Hans - Die Portugiesen in Antwerpen (1567-1648)... pp. 222-223.
} 
não forem parentes ou parceiros, pode haver mais litígios, logo mais atos notariais. A comprovar-se, isso revelaria uma maior endogamia em 1596 e menor em 1606, mas esta é uma hipótese que não conseguimos confirmar.

De Amesterdão chegam apenas 4 letras. Proporcionalmente é uma quebra significativa: se para o período até 1596 representam 27\% do total, são apenas 3\% do conjunto de letras de 1605-1606. Madrid não aparece sequer ${ }^{26}$. A redução da visibilidade de Amesterdão em 1606 talvez se possa explicar pelo facto de a situação de guerra entre os Países Baixos espanhóis e as Províncias Unidas dificultar trocas comerciais e financeiras entre as duas cidades e respetivas comunidades. Tal não significa necessariamente que não haja relações de negócios entre as comunidades portuguesas presentes nessas duas cidades, as quais provavelmente passam por outros espaços.

$\mathrm{Na}$ área dos negócios em curso outras situações podem ser reportadas, como sejam três situações de falência ${ }^{27}$, uma parceria declarada ${ }^{28}$, uma procuração para administração de negócios ${ }^{29}$ ou ainda o arrendamento de um imóvel ${ }^{30}$.

Centremo-nos, por fim, nos contratos. Estes foram anotados sem menção de data, visto não sabermos quando foram efetivamente estabelecidos. Com a exceção do contrato das casas reais $^{31}$ e do contrato para o fornecimento de fardas ${ }^{32}$, as referências predem-se com contratos relativos a possessões portuguesas na costa atlântica africana: Angola ${ }^{33}$, Cabo Verde ${ }^{34}$ e São Tomé ${ }^{35}$, em que direta ou indiretamente estão envolvidos membros da comunidade portuguesa em Antuérpia. São mencionados no quadro de procurações e substabelecimento de poderes para a receção, venda e cobrança das mercadorias, que, como referido, já não são descarregadas em Antuérpia: no contrato de Angola, o negócio faz-se entre a Frísia e Hamburgo, no contrato de São Tomé, os agentes estão em Honte (a via ocidental do Escalda). O contrato de Cabo Verde traz por arrasto a menção a Cartagena das Índias, indiciando a interligação entre as possessões portuguesas, espanholas (por certo na sua direta relação com tráfico de escravos) e o Noroeste

\footnotetext{
${ }^{26}$ Sara Costa Pinto afirma que Madrid cresce em importância, enquanto sede da monarquia filipina, e como local onde se acordariam empréstimos à coroa (PINTO, Sara Maria Costa - A Companhia de Simón Ruiz... p. 106 e seguintes). O facto de Madrid perder expressão de 1596 a 1606 pode dever-se aos seguintes motivos: ou não há conflitos/recusas de pagamento; ou os financiamentos são concedidos à administração espanhola na Flandres (os asientos de segunda categoria) e não à administração central; ou os empréstimos à coroa passam por Lisboa, e por isso Lisboa surge à cabeça.

${ }^{27}$ N\#3568, fols. 223-223v; Gillis, Van den Bossche - Protocollen, 1606-1606. N\#3585 (fols. 1-437) (FelixArchief, Stadsarchief Antwerpen), N\#3585 fols. 353-353v; e N\#3586, fol. 60.

${ }^{28}$ N\#3568, fols. 248-249; e Gillis, Van den Bossche - Protocollen, en staten, 1605-1606. N\#3584 (fols. 1-430)

(FelixArchief, Stadsarchief Antwerpen), N\#3584 fols. 25-26.

${ }^{29} \mathrm{~N} \# 3568$, fols. 32v-34v; N\#3568, fols. 329-334; N\#3584, fols. 325v-326v.

${ }^{30} \mathrm{~N} \# 3584$, fols. 198.

${ }^{31} \mathrm{~N} \# 3568$, fols. 141-142.

${ }^{32} \mathrm{~N} \# 3584$, fols. $84-84 \mathrm{v}$.

${ }^{33} \mathrm{~N} \# 3568$, fols. 32v-34v.

${ }^{34} \mathrm{~N} \# 3568$, fols. $42-42 \mathrm{v}$.

${ }^{35} \mathrm{~N} \# 3568$, fols. $395-398 \mathrm{v}$.
} 
europeu. De mencionar ainda uma complexa disputa em 1606 em que se solicita o arresto de uma remessa de pau brasil para pagamento de uma dívida ${ }^{36}$.

De novo, e como hipótese, o facto de não haver, no ano de 1606, qualquer referência a esse tipo de contratos de grande envergadura, envolvendo articulações institucionais com os impérios ibéricos, pode indiciar que Antuérpia já está a ser relegada para segundo plano como espaço de corretagem destas mercadorias, visto que em 1596 ainda eram de Antuérpia os agentes responsáveis pela administração do comércio de produtos desses contratos. Com efeito, as (poucas) menções a mercadorias, em 1606, refletem-no, sendo exceção a canela (recebida em Hamburgo) e o gengibre em conserva. Refere-se ainda o trigo e os cereais, o açúcar e o pau do Brasil, as pedras preciosas, ou alguns produtos locais (lãs e ferragens).

Desta análise, pode-se concluir que os mercadores portugueses em Antuérpia se mantêm ativos, havendo mesmo entre 1596 e 1606 um crescimento tanto da própria comunidade em termos numéricos (questão a abordar no ponto seguinte), como dos seus negócios. Baseandose na família mais ou menos alargada para as suas atividades económicas, os portugueses recorrem a advogados de Antuérpia, emprestam ou usam crédito de espanhóis e flamengos. No tocante ao comércio e negócios, não se confirmam as hipóteses defendidas por Jessica Roitman para os grandes mercadores sefarditas de Amesterdão, nomeadamente de que evitariam fazer negócios com membros da sua comunidade étnica/religiosa, favorecendo antes relações comerciais mais soltas com holandeses, sendo esta uma das razões para o seu sucesso. ${ }^{37}$ Com efeito, e se tomarmos como exemplo os Rodrigues de Évora, os Ximenes ou os Jorge, os membros mais ativos, vemos que muitos dos seus parceiros são portugueses com quem partilham laços de parentesco. O raio de ação destes mercadores abrange Hamburgo, Flandres, Inglaterra, França, Itália, Península Ibérica, bem como os espaços atlânticos dos dois impérios. Note-se, para 1606, um franco aumento das operações financeiras, com Lisboa e Sevilha à cabeça, o que pode ser indício de comércio com estes dois portos, mas também de financiamento aos Filipes. Com efeito, Antuérpia emerge como um espaço privilegiado para estabelecer contactos com a administração espanhola, e daí derivam também vantagens para negócios de financiamento da administração filipina.

\footnotetext{
${ }^{36} \mathrm{~N} \# 3584$ fol 25 a 26.

${ }^{37}$ Roitman: "They all seemed to have eschewed intra-Sephardi networks" - ROITMAN, Jessica - The same but different? Intercultural trade and the Sephardim, 1595-1640. Leiden, Boston: Brill, 2011. p 275.
} 


\section{Análise social}

Para uma análise do perfil social, incluindo a dimensão das relações familiares, dos indivíduos que incorporam a comunidade portuguesa em Antuérpia, a reconstituição de genealogias seria de reconhecida utilidade. Todavia, qualquer tentativa de traçar árvores genealógicas a partir de dados recolhidos dos atos notariais revela-se um trabalho muito complexo, forçosamente lacunar e pouco fiável. O mesmo indivíduo tem muitas variantes do seu nome, além de que os nomes de batismo e alguns apelidos se repetem dentro da mesma família, aparecendo também nos ramos colaterais. Só através do cruzamento com dados de outras fontes secundárias podemos tentar estabelecer laços de parentesco além dos referidos nos próprios documentos. Neste domínio, a tese de doutoramento de Florbela Frade ${ }^{38}$ revelouse particularmente útil, já que a autora recorre a diferentes fontes primárias, nomeadamente aos processos inquisitoriais. Ainda assim, para estudos prosopográficos, os atos notariais podem revelar-se uma boa fonte para confirmar percursos biográficos.

Para este trabalho, a grafia dos nomes foi atualizada. Quando não se encontrou a confirmação de que um indivíduo tinha origem portuguesa, não foi considerado (ex. Diego Pardo); por outro lado, quando surgem dois indivíduos em que há uma coincidência parcial dos apelidos e há simultaneamente outros dados que confirmam que se trata do mesmo indivíduo, é anotado o nome que aparece com mais frequência (ex: Alonso Peres e não Alonso Peres de Oliveira, com uma única ocorrência). Não havendo essa confirmação, registam-se como dois indivíduos distintos.

Procuremos de seguida inserir a presente vertente de análise numa leitura contextual. O embargo do porto de Antuérpia foi um golpe na atividade económica da cidade, mas a saída de membros da comunidade portuguesa já tinha começado antes, desde a "Fúria espanhola" em novembro de 1576. Partiam para Amesterdão, Midelburgo e Roterdão, para Hamburgo e Colónia, Paris, Bordéus, Cambrai e Lyon $^{39}$. As razões seriam certamente a insegurança de pessoas e bens, mas também de ordem religiosa. Assim, se os dados relativos a 1571 apontam para a presença de 101 membros da Nação portuguesa, (uma associação de representação dos interesses dos mercadores portugueses em Antuérpia), em 1591 os membros seriam apenas $57^{40}$.

As informações recolhidas a partir dos documentos notariais não permitem sempre apurar se os indivíduos fazem parte da Nação portuguesa. Os documentos relativos a 1596 por norma têm a menção expressa da "nacionalidade" e se se trata de residentes ou pessoas estantes.

\footnotetext{
${ }^{38}$ FRADE, Florbela Veiga - As relações económicas e sociais das comunidades sefarditas portuguesas - O trato e a família, $1532-1632$...

${ }^{39}$ POHL, Hans - Die Portugiesen in Antwerpen (1567-1648)... p.65.

${ }^{40}$ POHL, Hans - Die Portugiesen in Antwerpen (1567-1648)... p. 66
} 
São estes os dados que permitem distinguir entre portugueses e espanhóis, e entre portugueses de Antuérpia e os de Portugal. O nome do indivíduo não serve de orientação, pois há uma tendência para traduzir os nomes de batismo para a língua em que o documento é redigido. Os livros notariais de 1606 raramente mencionam a "nacionalidade". Todavia, o facto de vários mercadores permanecerem na cidade, ou serem membros de famílias aí estantes, permite fazer a sua identificação, além do confronto com fontes secundárias.

Em 1596 identificam-se 42 portugueses residentes em Antuérpia. Entre estes, há vários que já residiam na cidade antes de 1585, os próprios ou membros da respetiva família. Em 1571 encontram-se os apelidos Fernandes, Dinis, Lopes, Veiga, Soeiro, que também surgem em 1596. Entre os indivíduos identificados em 1596 que pertencem a famílias listadas em $1571^{41}$, encontram-se os Ximenes (Emanuel, Gonçalo, Duarte, Rodrigo, Nicolau, André; Gracia Rodrigues e Fernando em Florença); Teixeira - Faleiro (Manuel e António); Rodrigues de Évora (Nicolau e Simão); Fernandes de Lião (Diogo Duarte, Catarina e Leonor Ferreira; Simão Ferreira morreu em Goa em 1594); Clara Lindo - filha de Jerónimo Lindo; Álvaro Nunes (o próprio?); Violante Dias - filha de Miguel Dias; João Mendes Henriques - herdeiro de Manuel Henriques; Henrique Nunes.

Filipe Jorge já faleceu em 1606, mas o seu nome reaparece na sociedade constituída pela sua viúva e filhos, "Margarida Nunes e herdeiros de Filipe Jorge”, com o filho Luís Álvares Jorge como administrador da casa. Em 1606, entre outros, contam-se os Godines, Mendes Pinto, Brandão, Angel, Gomes de Alter, Gomes de Oliveira, Guerra (estante), Ulhoa, Pimentel. Aliás, a comparação entre os dois anos revela uma maior diversidade de apelidos em 1606: Antuérpia não tinha perdido ainda a sua atratividade como local de residência para os mercadores portugueses $^{42}$. Confirma-se assim que os portugueses não abandonaram Antuérpia, depois de ultrapassados os primeiros anos de incerteza ${ }^{43}$.

Como se pode concluir da lista acima apresentada, alguns permaneceram na cidade após a sua subordinação ao poder filipino, outros, que escaparam num primeiro tempo, acabaram por regressar $^{44}$ : Peres, Rodrigues de Andrade, Aires Gonçalves, Frances (ou Francês), Correia, são apelidos referenciados numa lista de residentes de 1591, e nos atos notariais de 1596, mas que não constam das listas de 1571 , de onde se pode inferir que chegaram à cidade já em pleno

\footnotetext{
${ }^{41}$ Elaborado a partir da lista de Portugueses com família de 1571, em FRADE, Florbela Veiga - As relações económicas e sociais das comunidades sefarditas portuguesas - O trato e a família, 1532 - 1632... p. 367

${ }^{42}$ POETTERING, Jorun - Migrating Merchants... pp. 104-105. É uma emigração de cristãos-novos que escolhem a dedo os locais onde podem prosseguir as suas atividades comerciais, diferente da primeira vaga de emigração, mais precipitada, no reinado de D. Manuel.

${ }^{43}$ FRADE, Florbela Veiga - As relações económicas e sociais das comunidades sefarditas portuguesas - O trato e a família, 1532 - 1632... pp. 65-71.

44 POETTERING, Jorun - Migrating Merchants ... p. 105.
} 
domínio dos Habsburgo. Há mesmo famílias que optaram por emigrar para Antuérpia durante o final do século XVI e inícios do século XVII ${ }^{45}$. A escolha do novo espaço para viver poderá estar ligada aos laços de parentesco com membros da família que residem em Antuérpia.

Uma das características destes mercadores é a de escolherem como parceiros de negócio membros da sua família, mais ou menos alargada. Nos dados extraídos verifica-se a existência de várias parcerias entre parentes. Assim, em 1596 Manuel Teixeira associa o seu filho António Faleiro como procuradores subestabelecidos na administração delegada do contrato de Angola; mais tarde, em 1606, António Faleiro aparece associado ao irmão André em múltiplos negócios (estão entre os membros da comunidade portuguesa mais referidos nos livros notariais desse ano); o mesmo contrato de Angola associa dois irmãos (o contratador João Nunes e Henrique Nunes Correia, seu procurador em Antuérpia). Também o contrato de Cabo Verde é um negócio de família: Luís Álvares Caldeira é referido como administrador em Cartagena das Índias, em nome dos seus irmãos contratadores, António e Diogo Nunes Caldeira, deixando como procuradora em Antuérpia a esposa, Clara Lindo.

Os Ximenes, família com ramificações em Florença (onde se encontram Nicolau, sua mãe Gracia Rodrigues e o tio Fernando) e Lisboa (André Ximenes), colaboram entre si numa parceria fixa entre os irmãos Gonçalo e Duarte Ximenes, aos quais se junta por vezes outro irmão, Emanuel Ximenes, mas sem lhes estar associado. Uma parceria entre vários irmãos ${ }^{46}$ é a que se apurou em 1596 entre Diogo Mendes, que em 1590 em Lyon estabelece uma procuração ao "conpanero en negocios" e irmão Fernando Dias, que por sua vez, em 1596, subestabelece esse poder em Heitor Mendes (outro irmão, residente em Lisboa) e Luís Mendes de Olivença para cobrarem uma letra de câmbio dada em Besançon, em $1589^{47}$. Em 1606 ainda há traços desta família em Antuérpia, com a referência à sociedade "Violante Mendes e herdeiros de Manuel Jorge" (que era irmão de Filipe Jorge, já mencionado) no quadro da cobrança de uma letra. Os pagadores recalcitrantes, Pedro e Mateus da Veiga, também são uma parceria entre dois irmãos e um terceiro sócio e cunhado, Luís Ferreira, membros muito ativos e que na bancarrota são

\footnotetext{
${ }^{45} \mathrm{~N} \# 3584$, fol. 171: certidão solicitada por João Lopes de Évora em como chegou a Antuérpia para nela ter domicílio. Simão Rodrigues de Évora, provável parente, é uma das testemunhas. N\#3585, fols. 362-364v: procuração para administração do património deixado em Lisboa, por morte de António de Orta, patriarca da família, durante a viagem que o levaria com a esposa e filha menor para Antuérpia. É de considerar a hipótese de se tratar de um caso de uma família que aproveitou o perdão geral de 1605. EBERT, Christopher - "Early Modern Atlantic Trade and the Development of Maritime Insurance to 1630 "... p. 97: "Antwerp was the premier magnet for Portuguese immigration until 1609, when Amsterdam surpassed it".

${ }^{46}$ FRADE, Florbela Veiga - As relações económicas e sociais das comunidades sefarditas portuguesas - O trato e a família, $1532-1632 \ldots$ p. 401.

${ }^{47} \mathrm{~N} \# 3568$, fols. 215-217v.
} 
auxiliados graças ao mecanismo do endosso por outros mercadores da praça de Antuérpia, com os quais também têm laços de parentesco (Simão Rodrigues de Évora e Duarte e Gonçalo Ximenes).

Nestas famílias de parceiros de negócios, os laços são reforçados por casamentos: é o caso de Simão Rodrigues de Évora, que celebra um contrato de casamento da filha, Gracia Rodrigues, com o sobrinho, Francisco Rodrigues de Évora, filho do seu irmão Lopo ${ }^{48}$, o qual associará mais tarde às suas atividades comerciais. Esta promessa de casamento não impede que quatro meses mais tarde, Francisco solicite o arresto dos bens da sociedade de Pedro e Mateus da Veiga e Luís Ferreira que estão na posse do seu tio Simão e de Duarte e Gonçalo Ximenes, seus primos, em favor de seu pai e irmãos ${ }^{49}$. Nos quatro outros contratos de casamento apurados há mais um caso de casamento entre primos (António Faleiro e Ana Solis, noiva que veio de Lisboa). Em geral, nos vários casais identificados (em procurações, testamentos e outros atos), verifica-se que os cônjuges são sempre portugueses. Há um único casal flamengo/ português: Cornelis Snellinck e Leonor da Veiga. Casados em Antuérpia, onde nasceu um filho, transferem-se para Amesterdão, onde Cornelis Snellinck se torna um dos principais parceiros de negócios de Manuel Rodrigues da Veiga, um importante mercador e um dos três casos de estudo de Jessica Roitman ${ }^{50}$. A família Snellinck estava associada a negócios com outros portugueses em 1596 (Adrien Snellinck era agente de Alonso Peres num negócio na Inglaterra ${ }^{51}$ ).

Como se pode ver a partir de alguns dos exemplos apresentados no capítulo relativo à atividade económica, frequentemente estas associações de negócios baseadas na família estabelecem-se à distância. A mobilidade do grupo e a implantação de parentes em diferentes pontos do globo que aqui verificamos é uma característica reconhecida pela historiografia ${ }^{52} \mathrm{e}$ patente nos documentos analisados. O êxodo de Antuérpia transfere membros das várias famílias para outros espaços europeus, já identificados de forma não exaustiva no capítulo anterior, onde alguns acabam por se instalar. Veja-se o caso dos Ximenes: Rui Nunes Ximenes (pai de Gonçalo, Duarte e Emanuel), tornou-se cidadão de Colónia ${ }^{53}$, mas os seus filhos regressam a Antuérpia, onde vivem em 1596 e 1606. Gracia Rodrigues, esposa de Rui Nunes Ximenes e entretanto viúva - e também irmã de Simão Rodrigues de Évora, barão de Rodes -,

\footnotetext{
${ }^{48} \mathrm{~N} \# 3585$, fols. $24-25 \mathrm{v}$.

49 N\#3586, fol. 60v.

${ }^{50}$ ROITMAN, Jessica - The same but different? Intercultural trade and the Sephardim, 1595-1640... Cap. III.

${ }^{51} \mathrm{~N} \# 3568$, fols. $236-237$ e fol. 377.

${ }^{52}$ POETTERING, Jorun - Migrating Merchants... p. 105; RIBEIRO, Ana Sofia - "The evolution of norms in trade and finantial networks in the first global age: the case of the Simon Ruiz's network". In ANTUNES, Cátia; POLÓNIA, Amélia (eds.) - Beyond Empires: global, self-organizing, cross-imperial networks, 15001800. Leiden: Brill, 2016. Cap. I, pp.15-16.

${ }^{53}$ FRADE, Florbela Veiga - As relações económicas e sociais das comunidades sefarditas portuguesas - O trato e a família, $1532-1632 \ldots$ pp. 283 e 402.
} 
encontra-se Florença em 1596, onde vive também o tio Fernando Ximenes, e de onde mantém correspondência de negócio com os filhos ${ }^{54}$. É o que se deduz de um documento em que Emanuel Ximenes solicita ao irmão Duarte a partilha dos dinheiros e juros do livro das contas, ao que este responde que devem aguardar autorização da mãe e do tio em Florença, como representantes dos irmãos menores. Na mesma resposta, Duarte sugere "para que no este el dinero ocioso... procurara remetir lo que sobrare de dinero al dicho libro por quenta e beneficio del mismo libro a las plaças que paresciere de mas provecho", num exercício de equilíbrio entre a boa gestão do património e a manutenção da paz familiar.

Na família Fernandes ${ }^{55}$ : Luís Fernandes é dador de uma letra de câmbio em Hamburgo, com data anterior a 1596, com destino a Florença ou Veneza ${ }^{56}$. Em 1596 já consta como residente em Antuérpia, de onde envia um criado para servir o seu filho Rafael Fernandes em Sevilha ${ }^{57}$. Dez anos mais tarde está em Amesterdão para testemunhar a sentença num litígio que opõe o seu filho Gabriel Fernandes a Lopo Sanches ${ }^{58}$. Gabriel é por várias vezes referido como estando em Londres ${ }^{59}$. Um terceiro filho de Luís Fernandes é Manuel Rodrigues da Veiga, o importante mercador e primeiro cidadão português de Amsterdão estudado por Jessica Roitman, que ainda em 1606 se encontra ligado por negócios a Lopo Sanches ${ }^{60}$.

Quando se lê "residente" no documento notarial, deve entender-se como se tratando de uma residência relativamente estável até ao momento da feitura do documento, pois são vários os exemplos de negociantes dados como residentes e que são referenciados noutros estudos como membros de outras comunidades mercantis portuguesas noutros espaços geográficos. É o caso de André Faleiro ${ }^{61}$ ou de Luís Vaz Pimentel ${ }^{62}$ referidos como residentes em Antuérpia, mas que se estabelecem em Hamburgo, de Gaspar Nunes e de Gaspar Sanches em Amesterdão ${ }^{63}$, ou de Gabriel Fernandes, que vive em Londres em $1606^{64}$. Em 2 de março de 1606, Fernando de Mercado requer ao notário uma certidão de residência em Antuérpia desde

\footnotetext{
${ }^{54} \mathrm{~N} \# 3568$, fols. 352-354.

${ }^{55}$ Para mais pormenores sobre a geografia coberta pela família Fernandes, vide FRADE, Florbela Veiga - As relações económicas e sociais das comunidades sefarditas portuguesas - O trato e a família, 1532 - 1632... p. 293.

${ }^{56} \mathrm{~N} \# 3568$, fols. 248-249.

${ }^{57} \mathrm{~N} \# 3568$, fols. $159-159 \mathrm{v}$.

${ }^{58} \mathrm{~N} \# 3586$, fols. 140-142v.

${ }^{59} \mathrm{~N} \# 3585$, fol. 339; N\#3586, fols. 303-304.

${ }^{60} \mathrm{~N} \# 3586$, fols. 173-174v: procuração para Lisboa para cobrança de um endosso de Manuel Rodrigues Veiga em favor de Lopo Sanches no quadro de uma sentença em favor de Sanches: a descrição do capital endossado revela contactos de Rodrigues Veiga com Pernambuco e Lisboa.

${ }^{61}$ POETTERING, Jorun - Migrating Merchants... p. 232.

62 POETTERING, Jorun - Migrating Merchants... p. 234.

${ }^{63}$ SILVA, José Gentil da - "Trafics du Nord, marchés du «Mezzogiorno», finances génoises: recherches et documents sur la conjoncture à la fin du XVIe siècle"... p. 51.

${ }^{64} \mathrm{~N} \# 3584$, fols. 222-222v; N\#3586, fols. 140-142v.
} 
fevereiro do mesmo ano, tal como o seu irmão Simão ${ }^{65}$. Todavia, em 26 de maio seguinte, Fernando de Mercado é procurador de Beatriz Rodrigues em Londres. ${ }^{66}$.

Os principais "protagonistas" dos documentos notariais são homens. Nos dois anos em conjunto, são apenas 45 (7,4\% do total de indivíduos) os registos de mulheres contra 563 de homens (portugueses e estrangeiros). Quando são referidas, normalmente estão sujeitas a uma tutela masculina, seja pai, marido, irmão. Ainda assim, algumas destas mulheres têm um papel ativo nos negócios: além dos já referidos litígios de Maria Gomes, viúva de Nicolau Rodrigues de Évora, veja-se o caso de Clara Lindo, mulher de Luís Álvares Caldeira, nomeada em 1595 sua procuradora e que em 1606 ainda se ocupa de uma cobrança no tribunal de Angers ${ }^{67}$, ou de Leonor Rodrigues ${ }^{68}$, também procuradora do marido, Emanuel Dias, ou de Margarida Nunes, viúva de Filipe Jorge e que dá nome à sociedade "Margarida Nunes e herdeiros de Filipe Jorge", ou da sua cunhada, Violante Mendes e a sociedade "Violante Mendes e herdeiros de Manuel Jorge", ou ainda Clara Peeters, ${ }^{69}$ pagadora de uma letra de câmbio dada em Amsterdão a Gaspar Ruiz.

Uma última referência à religião: é consensual entre os historiadores o facto de que grande parte destes mercadores são cristãos-novos. Alguns estudiosos debruçam-se sobre a questão de estes terem regressado à religião hebraica professada pelos seus antepassados ou de, pelo contrário, se terem mantido católicos. É evidente que tal informação não pode constar de documentos notariais; inversamente, o respeito dos formalismos religiosos inerentes à sociedade flamenga, sob domínio castelhano, pode ser confirmado. Assim, são vários os atos confirmados por juramentos sobre a sagrada escritura (entenda-se o Novo Testamento), ou o caso do casamento ${ }^{70}$ entre os primos Gracia Rodrigues e Francisco Rodrigues da Veiga, que será "com la bendicion de nuestro s.r y por la permission de nuestra madre santa yglesia". $\mathrm{O}$ pai da noiva, Simão Rodrigues de Évora, promete "de aver la dispensacion de su santidad". Há ainda a referência às irmãs Leonor e Catalina Nunes Peres, monjas professas no mosteiro de Santa Clara em Antuérpia. Na família Ximenes, faz-se um membro do clero, Manuel Ximenes, tio dos herdeiros de Rui Nunes de Évora. O lado material da relação com a Igreja também é referido, quando Catarina Vaz e o marido dão procuração para Lisboa para cobrança de "hua tença de seys mil reis que a dita Catarina Vaz tem em cada hu anno nas obras pias na cidade de Lisboa"71. Em Novembro de 1606, Emanuel Ximenes e Guilielmus Veraneman, reitor do

\footnotetext{
${ }^{65} \mathrm{~N} \#$ 3584, fols. 311-311v.

${ }^{66} \mathrm{~N} \# 3585$, fols. 179-180.

${ }^{67} \mathrm{~N} \# 3586$, fols. 213-214.

${ }^{68} \mathrm{~N} \# 3584$, fols. 409; N\#3585, fols. 179-180.

${ }^{69} \mathrm{~N} \# 3568$, fols. 97v-98v.

${ }^{70} \mathrm{~N} \# 3585$, fols. 24-25v.

${ }^{71} \mathrm{~N} \# 3586$, fols. 298-299v.
} 
Colégio da Sociedade de Jesus da universidade de Lovaina, estabelecem um acordo de pagamento relativo à renda de uma propriedade em Melle, propriedade de Ximenes ${ }^{72}$. A única referência a uma possível pertença à comunidade sefardita é a já referida procuração de André Faleiro, em nome da gente da Nação Portuguesa. Assim, o que é visível pela sociedade local é antes uma perfeita adesão aos preceitos religiosos em vigor na cidade - condição por certo inultrapassável em territórios ainda sob domínio dos "Reis Católicos".

\section{Considerações finais}

Esta é a comunidade de mercadores portugueses em Antuérpia na transição do século XVI para o século XVII que este trabalho conseguiu apresentar. As informações coligidas a partir dos livros do tabelião Gillis van den Bossche apresentam-nos um grupo em crescimento, mesmo que tenha sofrido temporariamente uma quebra numérica com a tomada da cidade, sendo esse crescimento visível tanto em número de indivíduos como em atividades económicas. Se os seus parceiros são sobretudo portugueses, estes indivíduos não deixam de estabelecer relações de negócio com flamengos e espanhóis. As relações familiares e de sociabilidade são predominantemente intra-comunitárias, mas a documentação revela igualmente contactos com os homens de negócio locais.

O seu cosmopolitismo revela-se nas línguas que $\mathrm{usam}^{73}$, nas relações estabelecidas com agentes de outras origens, na sua mobilidade, na sua integração nas práticas religiosas e nas formalidades jurídicas e judiciais da cidade. Estão envolvidos no comércio de produtos locais e exóticos, no financiamento à coroa filipina, no mercado de seguros e no mercado de câmbios. Os seus negócios abarcam o noroeste europeu em articulação com a Península Ibérica e os impérios português e castelhano.

Além da elaboração de um perfil sócio-económico destes agentes, a questão que conduziu à elaboração deste trabalho foi a de tentar descortinar a razão porque, apesar do embargo imposto pelas Províncias Unidas a Antuérpia, a comunidade portuguesa deu continuidade à sua atividade a partir da Flandres. Uma possível explicação pode ser precisamente a facilidade em prosseguirem oportunidades de negócio que envolvem os vários espaços referidos, a partir de Antuérpia, que se mantém como centro de negócios. Isso é, a nosso ver, decorrente do acesso facilitado à coroa espanhola e aos seus representantes na Flandres e às necessidades de financiamento da mesma, bem como das redes de negócios já instaladas na cidade, entretanto, desenvolvidas

\footnotetext{
${ }^{72}$ N\#3586, fols. 332-333.

${ }^{73}$ Apesar de ser dominante o uso do espanhol nos atos, o neerlandês é usado em 19\% (1596) e 10,2\% (1606) dos atos, o francês em 10,4\% e em 18\%, respetivamente. Há ainda documentos escritos em latim, português e italiano.
} 
e consolidadas. Os dados económicos e os indicadores sociais recolhidos apontam para a contínua importância da praça entre os espaços de negócios frequentados pelos mercadores portugueses.

\section{Fontes}

Gillis, Van den Bossche - Protocollen, en staten en rekeningen, 1596-1596. N\#3568 (fols. 1422) (FelixArchief, Stadsarchief Antwerpen). Disponível em WWW:<URL: https://felixarchief.antwerpen.be/detailpagina?invnr=N_3568\&page=1\&pageSize $=10$ \&type $=$ master $>$.

- - Protocollen, en staten, 1605-1606. N\#3584 (fols. 1-430) (FelixArchief, Stadsarchief Antwerpen). Disponível em WW: <URL: https://felixarchief.antwerpen.be/detailpagina?invnr=N_3584\&page $=1 \&$ pageSize $=10$ \&type $=$ master $>$.

— - Protocollen, 1606-1606. N\#3585 (fols. 1-437) (FelixArchief, Stadsarchief Antwerpen). Disponível em WW: $<$ URL: https://felixarchief.antwerpen.be/detailpagina?invnr=N 3585\&page=1\&pageSize $=10$ \&type $=$ master $>$.

- - Protocollen en staten, 1606-1606. N\#3586 (fols. 1-482) (FelixArchief, Stadsarchief Antwerpen). Disponível em WWW:<URL: https://felixarchief.antwerpen.be/detailpagina?invnr=N 3586\&page $=1 \&$ pageSize $=10$ \&type $=$ master $>$.

\section{Bibliografia}

ANTUNES, Cátia - Globalisation in the Early Modern period: the economic relationship between Amsterdam and Lisbon, 1640 - 1705. Amesterdão: Aksant, 2004.

CLAVERÍAS, Belén Moreno - ¿Cómo se construye la historia económica? El uso de los documentos notariales para las práticas de historia económica en el marco del EEES. IX Encuentro de Didáctica de la Historia Económica, Toledo 24 e 25 de junho de 2010. [Em Linha] Toledo: [s.n.], 2010. Disponível em WWW: $<$ URL:https://www.aehe.es/wpcontent/uploads/2010/09/moreno.pdf $>$.

EBERT, Christopher - "Early Modern Atlantic Trade and the Development of Maritime Insurance to 1630". Past and Present. [Em Linha] Oxford: Oxford Univesity Press. Vol. 213, n. 1 (Nov. 2011). pp. 87-114. Disponível em WWW:<URL: https://academic.oup.com/past/article/213/1/87/1585311>.

FRADE, Florbela Veiga - As relações económicas e sociais das comunidades sefarditas portuguesas - O trato e a família, 1532 - 1632. Lisboa: Faculdade de Letras da Universidade de Lisboa. 2006. Tese de doutoramento.

FREIRE, A. Braamcamp - Noticias da Feitoria da Flandres: precedidas dos Brandões poetas do cancioneiro. Lisboa: Arquivo Histórico Português, 1920. 
GELDERBLOM, Oscar-Cities of Commerce: the institutional foundations of the international trade in the Low Countries, 1250-1650. New Jersey: Princeton University Press, 2013. ISBN 9780691142883.

GORIS, Jan Albert - Étude sur les Colonies Marchandes Méridionales (Portugais, Espagnols, Italiens) à Anvers de 1488 à 1567: Contribution à l'Histoire des Débuts du Capitalisme Moderne. Nova Iorque: Franklin, 1971.

PINTO, Sara Maria Costa - A Companhia de Simón Ruiz. Análise espacial de uma rede de negócios no século XVI. [Em Linha] Porto: [Edição do Autor], 2012. Tese de doutoramento. Disponível em WWW:<URL: https://hdl.handle.net/10216/67323>.

POETTERING, Jorun - Migrating Merchants: Trade, Nation and Religion Between Hamburg and Portugal in the 17th Century. Tradução de Kenneth Kronenberg. Berlin, Boston: De Gruyter Oldenbourg, 2019. ISBN 9783110472103.

POHL, Hans - Die Portugiesen in Antwerpen (1567 -1648); zur Geschichte einer Minderheit. Wiesbanden: Franz Steiner Verlag GmbH, 1977. ISBN 3-515-02380-1.

PUTTEVILS, Jeroen - “«Eating the bread out of their mouth»: Antwerp's export trade and generalized institutions, 1544-5". The Economic History Review. [Em Linha] Vol 68, ${ }^{\circ}$ 4 (Maio 2015) pp. 1339-1364. Disponível em WWW:<URL:https://doi.org/10.1111/ehr.12103>.

RIBEIRO, Ana Sofia - "The evolution of norms in trade and finantial networks in the first global age: the case of the Simon Ruiz's network”. In ANTUNES, Cátia; POLÓNIA, Amélia (eds.) - Beyond Empires: global, self-organizing, cross-imperial networks, 1500-1800. Leiden: Brill, 2016.

ROITMAN, Jessica - The same but different? Intercultural trade and the Sephardim, 15951640. Leiden, Boston: Brill, 2011. 328 p. ISBN 9789004202771.

SILVA, José Gentil da - "Trafics du Nord, marchés du «Mezzogiorno», finances génoises: recherches et documents sur la conjoncture à la fin du XVIe siècle". Revue du Nord. [Em Linha] Lille. Vol. 41, n. 162 (Abril-Junho 1959). pp. 129-152. Disponível em WWW: $<$ URL:https://www.persee.fr/doc/rnord_0035-2624_1959_num_41_162_2331>.

SPUFFORD, Peter - "From Antwerp and Amsterdam to London: The Decline of Financial Centres in Europe”. De economist. [Em Linha] Países Baixos. ISSN: 1572-9982. Vol. 154, n. 2 (Fev. 2006). pp. 143-175. Disponível em WWW:<URL: https://doi.org/10.1007/s10645-006-9000-7>.

TRIVELLATO, Francesca - The familiarity of strangers the Sepahrdic diaspora, Livorno, and the cross-cultural tradein the early modern period. New Haven, Londres: Yale University Press, 2009.

VÁZQUEZ DE PRADA, Valentín - Lettres Marchandes d'Anvers. Paris, S.E.V.P.E.N., 1960. 